\title{
GOVERNANÇA NO TERCEIRO SETOR: estudo sobre uma organização francesa do século XIX
}

\section{1- Marco Antonio Figueiredo Milani Filho*}

Doutor em Controladoria e Contabilidade pela Universidade de São Paulo (USP).

Professor do Programa de Pós-Graduação em Ciências Contábeis da Universidade Presbiteriana Mackenzie (PPGCC/UPM).

marcomilani@mackenzie.br

http://lattes.cnpq.br/4651759467054939

\section{2- Aida Maria Mendes Milani}

Mestre em Controladoria Empresarial pela Universidade Presbiteriana Mackenzie (UPM).

Pesquisadora do Núcleo de Estudos do Terceiro Setor da Universidade Presbiteriana Mackenzie (NETS/UPM).

aidamilani@yahoo.com.br

http://lattes.cnpq.br/3141576477234059 


\title{
GOVERNANÇA NO TERCEIRO SETOR: ESTUDO SOBRE UMA ORGANIZAÇÃO FRANCESA DO SÉCULO XIX
}

\section{RESUMO}

A elaboração deste trabalho foi motivada pela possibilidade de identificação, na estrutura organizacional de entidades do passado, das práticas e mecanismos de governança atualmente recomendados. O objetivo deste estudo exploratório foi identificar os principais elementos de governança de uma organização do Terceiro Setor do século XIX e compará-los com os atuais elementos relacionados às melhores práticas. Como base comparativa, adotou-se um conjunto de 24 itens de governança recomendados pelo IBGC, adaptados às organizações sem fins lucrativos. Pretendeu-se verificar a conformidade e a atualidade da estrutura de governança da Société Parisienne des Études Spirites - SPEE, a qual foi selecionada por sua relevância histórica e cultural, pois serviu de modelo para a criação de milhares de organizações religiosas semelhantes em todo o mundo. Efetuou-se uma pesquisa bibliográfica sobre os principais aspectos do projeto elaborado em 1868, por Allan Kardec, para a implantação de um conselho administrativo e para o desenvolvimento operacional da SPEE. Analisou-se a presença ou ausência das práticas de governança listadas pelo IBGC. A investigação apontou que 50\% dos modernos elementos de governança estavam integralmente contidos na proposta organizacional da SPEE, $25 \%$ estavam parcialmente presentes e os demais $25 \%$ estavam ausentes, sinalizando a importância com que essas práticas foram tratadas.

\section{Palavras-Chave}

Governança; melhores práticas; Sociedade Parisiense de Estudos Espíritas.

\section{GOVERNANCE IN THE THIRD SECTOR: STUDY OF A FRENCH ORGANIZATION FROM THE 19TH CENTURY}

\begin{abstract}
The preparation of this work was motivated by the possibility of identification of currently recommended practices and mechanisms of governance in the organizational structure of historical entities. The objective of this exploratory study was to identify the key elements of governance of an organization of the Third Sector established in the nineteenth century and compare them with current elements relating to best practice. As a comparative basis, a set of 24 items recommended by IBGC governance tailored to nonprofit organizations were adopted in the paper. It was intended to verify compliance and timeliness of the governance structure of the Société Parisienne des Etudes Spirites - SPEE, which was selected for its cultural and historical relevance, since it served as model for the establishment of thousands of similar religious organizations around the world. We conducted a literature search on the main aspects of the project prepared in 1868 by Allan Kardec, for the deployment of an board of directors and the operational development of the SPEE. We analyzed the presence or absence of governance practices listed by IBGC. This research found that $50 \%$ of the modern elements of governance were fully contained in the organizational proposed to SPEE, $25 \%$ were partially present and the remaining $25 \%$ were absent, indicating the importance with which these practices were addressed.
\end{abstract}

\section{Keywords}

Governance; best practices; Parisian Society for Spiritist Studies. 


\section{Introdução}

O conhecimento teórico desenvolvido desde os primeiros estudos de Spence e Zeckhauser (1971), Ross (1974) e Jensen e Meckling (1976), sobre o conflito de interesses e a assimetria informacional entre as partes relacionadas (principal e agente), favoreceu a ampla discussão sobre os elementos de governança presentes nos diferentes tipos de empresas, principalmente naquelas participantes ativas do mercado de capitais.

Para as organizações não governamentais sem fins lucrativos (as quais constituem o chamado Terceiro Setor), entretanto, as pesquisas sobre as práticas e políticas de governança ocupam um menor espaço na literatura científica, obtendo maior representatividade na última década devido a iniciativas de autores, em sua maior parte, de origem anglo-saxônica, como Steane e Christie (2001), Futter (2002), O'Reagan e Oster (2002), Ostrower (2007), entre outros.

O Terceiro Setor vem recebendo atenção crescente por parte da sociedade em geral, particularmente por seus financiadores, colaboradores e órgãos fiscalizadores, os quais passaram a exigir informações mais específicas e detalhadas sobre a aplicação de recursos e sobre os resultados obtidos. Transparência, prestação de contas, equidade e conformidade legal são palavras cada vez mais frequentes nos discursos dos gestores das organizações do Terceiro Setor, marcando a transição de uma administração anteriormente caracterizada pelo amadorismo para uma mais focada nas modernas técnicas de gestão e controle.

Atualmente, já se pode contar com diversas referências sobre as melhores práticas e mecanismos de governança, baseadas em anos de pesquisas acadêmicas e nas experiências de variadas organizações, independentemente do porte, segmento de atuação ou finalidade.

Apesar da discussão sobre os elementos de governança ser relativamente frequente nos ambientes corporativos e acadêmicos nos dias de hoje, tal fato não se mostra tão comum no passado. Obviamente, o termo governança assume significados específicos conforme o desenvolvimento teórico e o contexto considerado, mas isso não impediria que seus elementos, isoladamente ou em conjunto, estivessem presentes na estrutura organizacional das entidades de diferentes épocas.

A elaboração deste trabalho foi motivada pela possibilidade de identificação, na estrutura organizacional de entidades do passado que serviram de referência para organizações modernas, das práticas e mecanismos de governança atualmente recomendados.

Para se delimitar esta pesquisa, optou-se pela escolha de uma organização sem fins lucrativos com relevância histórica em seu segmento de atuação e que oferecesse material bibliográfico suficiente para a investigação científica. Dentre as alternativas viáveis, selecionou-se uma organização francesa do século XIX, denominada Société Parisienne des Études Spirites (Sociedade Parisiense de Estudos Espíritas - SPEE), a qual pode ser considerada a primeira organização espírita do mundo e cujo modelo estrutural influenciou, posteriormente, a criação de milhares de casas voltadas ao estudo doutrinário espírita e à prestação de serviços assistenciais em todos os continentes.

O objetivo deste estudo exploratório é identificar os principais elementos de governança da SPEE, em meados do século XIX, e compará-los com os atuais elementos divulgados na literatura especializada. Como base comparativa, adotou-se um conjunto de 24 práticas recomendados pelo Instituto Brasileiro de Governança Corporativa - IBGC, pertinentes às organizações do Terceiro Setor. (IBGC, 2009).

Sobre as limitações deste trabalho, destaca-se o fato do referencial teórico pertinente à relação principal-agente não pode ser aplicada diretamente às organizações do Terceiro Setor devido às questões da propriedade e das relações sociais e simbólicas presentes. Assim, exige-se um deslocamento da figura do principal, neste trabalho voltada para o Conselho de Administração. Outro ponto relevante é a abordagem de uma organização do século XIX sob lentes atuais, o que implica, por si só, numa transposição de contextos sócio-culturais.

Ao abordar o tema sob uma perspectiva histórica, espera-se que esta investigação contribua para a discussão conceitual da influência de aspectos organizacionais do passado em práticas relevantes de governança atuais, além de estimular novos estudos comparativos sobre as respectivas práticas em outros tipos de organizações tradicionais. 


\section{Referencial Teórico}

\subsection{Governança corporativa}

No ambiente empresarial, Jensen e Meckling (1976) definiram uma organização como um conjunto de contratos explícitos e implícitos que regulam o relacionamento entre os detentores do capital e os agentes contratados para gerir o capital. Nessa relação, os proprietários delegam autoridade executiva aos gestores, mas nem sempre esses últimos atuarão em prol dos interesses dos primeiros. $O$ trabalho de Jensen e Meckling, precedido pelos estudos de Spence e Zeckhauser (1971) e Ross (1974), desenvolveu um corpo teórico sobre a assimetria informacional e os possíveis conflitos existentes entre o principal e o agente denominado de Teoria da Agência e contribuiu, significativamente, ao embasamento conceitual do que hoje se considera Governança Corporativa.

Sob a perspectiva econômica, a concepção contratual da firma vem sendo adotada desde os estudos de Coase (1937), não se limitando à relação entre proprietários e gestores, mas também considerando todas as partes relacionadas (stakeholders), como os funcionários, fornecedores e credores, entre outros. Coase justifica a existência da empresa quando os seus custos de organização são inferiores aos custos de transação com o mercado e isso sinaliza, implicitamente, para a necessidade de relacionamentos estáveis e vantajosos entre as partes da organização como forma de reduzir os próprios custos. Essa reflexão abrange o que Jensen e Merckling (1976) e Fama e Jensen (1983) viriam a tratar nos chamados custos de agência, representados pelos esforços despendidos pelos proprietários para reduzir o conflito de interesses com os agentes gestores e, assim, objetivar a maximização da própria riqueza.

Segundo Brigham e Ehrhardt (2006), os principais custos de agência entre acionistas e administradores estão relacionados a:

- monitoramento das ações dos gestores, tais como auditoria.

- formulação de políticas e implantação de práticas específicas para limitar o comportamento indesejável dos administradores, tais como nomear investidores externos para o conselho de administração.

- exigências burocráticas para maior controle das ações executivas, que podem aumentar a morosidade na tomada de decisão dos gestores e prejudicar o aproveitamento de oportunidades que aumentariam a riqueza do próprio acionista.

Genericamente, a governança corporativa busca gerar condições para otimizar o desempenho de uma empresa protegendo os interesses de todos os stakeholders da organização.

Para a Comissão de Valores Mobiliários (2009), a governança corporativa caracteriza-se pelo conjunto de práticas que buscam "otimizar o desempenho de uma empresa ao proteger todas as partes interessadas, tais como investidores, empregados e credores, facilitando o acesso ao capital".

Segundo o Instituto Brasileiro de Governança Corporativa (IBGC, 2009), "governança corporativa é o sistema que assegura aos sócios-proprietários o governo estratégico da empresa e a efetiva monitoração da diretoria executiva $[$...]".

\subsection{Códigos de governança e melhores práticas}

Dentre os primeiros códigos de governança, destaca-se o relatório Cadbury, criado em 1992 no Reino Unido e que influenciou a produção de diversos trabalhos semelhantes abordando as relações entre acionistas, gestores, conselheiros e outras partes relevantes (Berghe \& Ridder, 1999; Gregory \& Simmelkjaer, 2002). A propagação dos códigos e das melhores práticas de governança voltadas para as administrações de governos de países desenvolvidos e em desenvolvimento, foi impulsionada por entidades internacionais, tais como o Banco Mundial e a Organização de Cooperação para o Desenvolvimento Econômico (OECD). No Brasil, dentre as entidades que se destacam por divulgarem recomendações sobre a governança corporativa estão a Comissão de Valores Mobiliários (2002) e o Instituto Brasileiro de Governança Corporativa (2009).

Atualmente, a literatura sobre o tema aponta a existência de 196 códigos distintos de melhores práticas de governança, em 64 países (Aguilera \& Cuervo-Cazurra, 2009). 
Há uma grande variedade de formuladores desses códigos, que não se limitam aos órgãos vinculados diretamente ao mercado de capitais, mas também representam associações profissionais, sindicatos, pesquisadores e entidades governamentais. A expressiva emissão de códigos de boa governança e melhores práticas foi acompanhada por um aumento na quantidade de trabalhos acadêmicos publicados, como observam Hermes, Postma e Zivkov (2007).

Aguilera e Cuervo-Cazurra (2009) destacam que ainda há uma perceptível predominância das abordagens normativas frente às necessidades de se conhecer os reais efeitos gerados pela aplicação das práticas prescritas de governança, chegando a existir divergências entre o que é recomendado pelos acadêmicos, por membros do Governo e pelos profissionais corporativos sob óticas específicas.

Sob a perspectiva empresarial, a adoção e divulgação dos códigos de governança atendem as necessidades de conformidade legal ou voluntária, objetivando-se a redução dos problemas de agência e a agregação de valor às organizações.

Conforme O'Shea (2005), em pesquisa realizada em países anglo-saxônicos, a maioria dos códigos voltados para as empresas tem recomendações, explícitas ou implícitas, sobre as seguintes práticas:

a) presença de membros independentes no Conselho de Administração;

b) clara divisão de responsabilidades entre o presidente do conselho e o presidente da diretoria executiva;

c) envio de informações oportunas e relevantes ao Conselho de Administração;

d) procedimentos formais e transparentes para a nomeação de novos membros executivos;

e) relatórios financeiros compreensíveis e completos;

f) manutenção de um sistema efetivo de controles internos.

Embora existam diferenças relacionadas às características da legislação vigente nos diversos países, dos órgãos normativos e das entidades independentes, os preceitos da boa governança corporativa têm alguns princípios comuns presentes na literatura consultada:

- Equidade: tratamento justo e igualitário dos acionistas, sem distinção ou favorecimento de majoritários ou minoritários, além de facultar a participação de todos nas assembléias gerais.

- Transparência: disponibilização e evidenciação das informações relevantes relacionadas ao desempenho empresarial e a riscos significativos de diferentes naturezas.

- Prestação de contas às partes que possuem interesse e legitimidade.

- Conformidade legal e comportamento ético, objetivando o estrito cumprimento das leis vigentes e das normas internas e externas que a entidade estiver sujeita.

Segundo o Instituto Brasileiro de Governança Corporativa (IBGC, 2005), as boas práticas de governança corporativa apresentam quatro princípios básicos:

a) transparência;

b) prestação de contas

c) equidade;

d) responsabilidade corporativa (sustentabilidade).

Além desses princípios, o IBGC (IBGC, 2009) explicita um conjunto classificado como melhores práticas, particularmente direcionadas ao Conselho de Administração (CA), listadas na Figura 1.

Os princípios do IBGC (IBGC, 2009) e de outras entidades, inicialmente direcionados às organizações empresariais, podem ser adaptados objetivando-se a respectiva aplicação às organizações não governamentais sem fins lucrativos, as quais constituem o chamado Terceiro Setor. Tal adaptação decorre do fato de que diferentes stakeholders têm interesses legítimos nas organizações, como por exemplo: Governo, doadores, usuários dos serviços prestados, entre outros. 
Figura 1: Tópicos das melhores práticas de governança relacionadas ao Conselho.

\begin{tabular}{|l|l|l|}
\hline a) Conselho de Administração (CA) & b) Conselho Consultivo & c) Missão do CA \\
\hline d) Competências e atribuições do CA & e) Separação de funções & f) Regimento interno do CA \\
\hline g) Presidente do CA & h) Comitês & i) Avaliação do CA e dos conselheiros \\
\hline j) Qualificação do conselheiro & k) Composição do Conselho & l) Prazo do mandato \\
\hline m) Idade & n) Porta-voz da sociedade & o) Avaliação da Diretoria executiva \\
\hline p) Planejamento da sucessão & q) Datas e pautas das reuniões & r) Documentação das reuniões \\
\hline s) Atas das reuniões & t) Auditoria Interna & u) Educação contínua dos conselheiros \\
\hline v) Auditoria independente & w) Conselho Fiscal & x) Código de conduta \\
\hline
\end{tabular}

Fonte: Adaptado de IBGC (2005)

\subsection{Governança em organizações do Terceiro Setor}

O Terceiro Setor, aqui definido como o ambiente que reúne as organizações privadas, autônomas e com administração própria, sem fins lucrativos, cuja atuação voluntária é dirigida a finalidades coletivas ou públicas (Fernandes, 1994; Paes, 2001; Fischer, 2002; Olak; Nascimento, 2008), possui uma participação econômica significativa. Conforme Salamon (1999), o setor emprega 19 milhões de trabalhadores remunerados em horário integral e movimenta quantias superiores ao Produto Interno Bruto de vários países. Flynn e Hodgkinson (2001) estimam essa movimentação em US\$ 1,6 trilhão.

Apesar de não contar com dados estatísticos recentes, estima-se que existam cerca de 338 mil entidades não governamentais sem fins lucrativos no Brasil (IBGC, 2009)

Uma das características do Terceiro setor é a heterogeneidade de seus próprios componentes, pois agrupa, em um mesmo espaço, entidades com diferentes funções sociais, tais como: defesa dos direitos civis, educação, saúde, assistência social, sindicalismo e religião, entre outros. Isso faz com que as especificidades de todas essas organizações não sejam comparáveis, mas elas podem ser analisadas sob aspectos mais genéricos.

Frumkin e Keating (2001) identificam quatro funções principais desse setor:

- Promoção do compromisso político e cívico;

- Prestação de serviços essenciais;

- Oferecimento de um ambiente para o empreendedorismo social;

- Expressão de crenças e valores.

O ponto mais destacado, o qual diferencia a abordagem tradicional da governança corporativa e aquela voltada para Organizações do Terceiro Setor (OTS), é a inexistência de proprietários com direito ao recebimento de benefícios econômicos. Tal fato faz com que, sob a perspectiva da Teoria da Agência (Jensen \& Meckling, 1976), o denominado principal da entidade sem fins lucrativos seja representado pelo Conselho da Administração e, em última instância (quando for o caso), a Assembléia Geral. Os agentes, por sua vez, permanecem como os gestores da organização, mas respeitando-se a impossibilidade de receberem benefícios financeiros quando a legislação assim determinar.

Assim, no Terceiro Setor, a relação entre possíveis expectativas conflituosas de agência ocorre, prioritariamente, na relação Conselho de Administração (e Assembléia Geral, quando existir) e os gestores, sem se confundir a figura do responsável jurídico pela OTS com seus outros stakeholders, como doadores, Governo e a própria sociedade civil que, apesar de possuírem interesse legítimo no desempenho dessas organizações, não atuam, especificamente, como principais.

O Conselho de Administração assume relevância fundamental na discussão sobre práticas e instrumentos de governança, não somente para empresas, mas também para as OTS. Mantidas as adequações necessárias pela ausência de proprietários ou acionistas, as boas práticas de governança se 
aplicam igualmente para todas as entidades, sejam elas de natureza governamental ou não governamental e, conforme suas finalidades, lucrativas ou não.

Os itens explorados pelo IBGC (IBGC, 2009) que envolvem as ações e procedimentos do Conselho de Administração objetivando-se a transparência, prestação de contas, equidade e sustentabilidade são apresentados a seguir.

\subsubsection{Transparência}

Objetivando promover a confiança entre as partes envolvidas, a transparência não possui, somente, a responsabilidade informar, mas deve fazer parte das práticas da entidade reconhecendo-se que a boa comunicação interna e externa exige o comprometimento da alta administração e do corpo diretivo. Essa prática não se restringe às informações financeiras obrigatórias, mas com ênfase, às informações voluntárias de diferentes natureza que reduzam a assimetria entre todos os stakeholders.

\subsubsection{Equidade}

Caracteriza-se pelo "tratamento justo e igualitário de todos os grupos minoritários [ ...] atitudes ou políticas discriminatórias, sob qualquer pretexto, são totalmente inaceitáveis" (IBGC, 2009). Em OTS, inexistindo a figura dos acionistas minoritários, os stakeholders (incluindo o público usuário dos serviços) devem receber, similarmente, tratamento sem qualquer tipo de privilégios que se configurem em benefícios diretos ou indiretos em detrimento do objeto social definido estatuariamente.

\subsubsection{Prestação de contas}

"Os agentes da governança devem prestar contas de sua atuação a quem os elegeu e respondem integralmente por todos os atos que praticarem no exercício de seus mandatos" (IBGC, 2009). Nesse caso, os gestores responsáveis pela condução da entidade e, ainda, os membros representativos da OTS, devem responder e oferecer as informações demandadas pelo Governo, doadores, fornecedores, usuários, voluntários e outros stakeholders sobre a origem e destino dos recursos recebidos, metas de desempenho, riscos envolvidos etc.

\subsubsection{Sustentabilidade}

"Conselheiros e executivos devem zelar pela perenidade das organizações (visão de longo prazo, sustentabilidade etc) e, portanto, devem incorporar considerações de ordem social e ambiental na definição dos negócios e operações" (IBGC, 2009). A responsabilidade social, o desempenho econômicofinanceiro e a conservação ambiental são os elementos da tripple bottom line modernamente discutida no âmbito empresarial. Sob o enfoque das OTS, as ações sociais e aquelas voltadas ao meio-ambiente são desenvolvidas com mais frequência, mas deve-se buscar atender a todos os fatores da sustentabilidade, o que implica em planejamentos estratégico e operacional voltados para a própria sobrevivência organizacional. Esse ponto, entretanto, necessita de abordagem cuidadosa, pois há OTS criadas para fins específicos que, uma vez atingidos, não justificam mais a existência da entidade (por exemplo, uma associação criada para auxiliar no combate a determinada doença que, posteriormente, foi erradicada). Os centros espíritas são concebidos objetivando a continuidade.

\subsection{Sociedade Parisiense de Estudos Espíritas - SPEE}

A Société Parisienne des Études Spirites (Sociedade Parisiense de Estudos Espíritas - SPEE), fundada por Allan Kardec em abril de 1858, era uma sociedade civil, de caráter cultural e filantrópico, voltada ao estudo científico e filosófico da Doutrina Espírita (Espiritismo) e de ramos do conhecimento a ela relacionados. A SPEE reunia associados e convidados para a discussão de fenômenos que atestavam a sobrevivência da alma e suas decorrentes consequências morais (Kardec, 1985a, 1985b).

Ao contrário das tradicionais estruturas religiosas da época, a recém apresentada Doutrina Espírita não se vinculava, em 1858, a modelos hierárquicos formalizados ou continha em seu escopo práticas, ritos ou 
símbolos que caracterizassem os seus adeptos. Nesse sentido, uma das preocupações constatadas na elaboração do primeiro regulamento interno para o funcionamento de suas reuniões foi a construção de uma estrutura organizacional que oferecesse elementos de transparência e equidade entre todos os seus associados.

As atividades da SPEE eram mantidas pelas contribuições financeiras espontâneas de seus associados e pelos recursos obtidos da venda de livros doutrinários de seu fundador.

Após dez anos de reuniões ininterruptas e produção de obras literárias sobre os princípios filosóficos, científicos e morais do Espiritismo, Kardec propõe, em 1868, um projeto de ampliação estrutural e de atividades da SPEE, incluindo a constituição de uma Comissão Central (que modernamente pode ser chamada de Conselho Administrativo). Tal iniciativa derivava da necessidade de atender à demanda crescente por informações doutrinárias solicitadas pelos inúmeros grupos espíritas que se formaram na França, em vários países europeus e no continente americano (inclusive o Brasil). Uma outra necessidade percebida por Kardec (1985c) para uma atuação mais efetiva da SPEE no movimento espírita emergente era a da manutenção da uniformidade doutrinária, buscando-se evitar o aparecimento de cismas e dissidências por interpretações equivocadas dos princípios e conceitos doutrinários.

A SPEE conheceu o seu auge no final do século XIX, perdendo representatividade no movimento espírita mundial a partir do início do século XX, quando as entidades federativas de cada país passaram a centralizar e organizar as associações espíritas locais.

\section{Procedimentos Metodológicos}

Para este trabalho exploratório e com abordagem qualitativa, realizou-se uma pesquisa bibliográfica e documental para o levantamento das características do objeto em estudo, neste caso específico, uma organização francesa do Terceiro Setor, fundada em meados do século XIX, a Sociedade Parisiense de Estudos Espíritas - SPEE e o seu conselho administrativo (Comissão Central). Essa organização foi selecionada por conveniência, seguindo-se os critérios de: a) relevância histórica da entidade; b) influência significativa da organização em determinado tema social; c) disponibilidade de dados.

Uma fonte histórica para a coleta de dados da SPEE foi o documento intitulado Projeto de 1868 (Kardec, 1985a), o qual descreve as características estruturais e operacionais do conselho de administração, assim como propõe o desenvolvimento de atividades relacionadas aos objetivos da referida organização. Acrescentam-se, ainda, a literatura pesquisada sobre as origens históricas e funcionamento de organizações espíritas, destacando-se: Federação Espírita Brasileira - FEB (1979), Garcia (1990), Pires (1990) e Spínola (2010).

Os itens utilizados para a identificação e análise dos elementos de governança presentes no objeto em estudo foram fundamentados nas melhores práticas de governança corporativa propostas pelo IBGC (2009), principalmente nos procedimentos recomendados para o Conselho de Administração, adaptando-os à realidade das entidades sem fins lucrativos (por exemplo, ausência de proprietários). Através da análise de conteúdo, conforme os procedimentos definidos por Bardin (2009), os itens de governança da SPEE foram categorizados e classificados como presentes, parcialmente presentes ou ausentes, de maneira e refletir a situação em que se encontrava essa organização sob uma perspectiva comparativa moderna. Esse fato gera algumas limitações ao estudo, especificamente decorrentes da abordagem com critérios desconhecidos para a época, mas permite, por sua vez, conhecer o estágio histórico encontrado sobre esses pontos.

\section{Análise de Dados}

\subsection{Elementos de governança}

A seguir, são apresentados os elementos de governança presentes e ausentes da SPEE, conforme os itens já expostos no Quadro 1. Considerando-se as limitações pertinentes à dimensão deste texto, as análises são sintetizadas para o aproveitamento adequado deste espaço 


\section{a) Conselho de Administração (CA) - Presente}

O Conselho de Administração da SPEE, também chamado de Comissão Central, possuía a responsabilidade máxima pelas decisões de fundo doutrinário na própria organização, além de expressar uma autoridade informal sobre todos os demais grupos com orientação espírita em estruturação na França e nos demais países. Não existia uma clara segregação entre as atividades do CA com a gestão operacional da SPEE. Na proposta de Kardec, a direção da SPEE confundia-se com as atribuições do próprio conselho.

\section{b) Conselho Consultivo - Ausente}

Segundo o IBGC (2009), a instalação de um Conselho Consultivo é “uma boa prática para [ ...] organizações do terceiro setor", pois permite que conselheiros independentes possam contribuir para o desenvolvimento da entidade. O papel, as responsabilidades e o âmbito de atuação dos conselheiros consultivos devem ser claramente definidos. No caso da SPEE, não se previa a participação de conselheiros independentes. Essa situação pode ser justificada pela própria necessidade de coesão e convergência do pensamento doutrinário, o qual deveria ser discutido por membros com reconhecido grau de assimilação do conteúdo teórico espírita, afastando a participação de membros sem essa qualificação. Sob a ótica da governança, há uma clara distinção entre os conselhos de administração e consultivo, pois o primeiro é um dos órgãos de poder da organização, enquanto o segundo é, apenas, de suporte.

\section{c) Missão do Conselho de Administração - Presente}

A missão manifesta do CA da SPEE voltava-se para a atuação externa e podia ser expressa como a de organizar e consolidar o movimento espírita emergente através da validação e divulgação do corpo teórico doutrinário, assim como prevenir e administrar situações de conflitos de interesses ou de divergência de opiniões, a fim de que o esclarecimento racional sobre as questões conceituais conflitantes sempre prevalecesse.

\section{d) Competências e atribuições do CA - Presente}

As competências e atribuições declaradas pelo CA da SPEE são:

1 O cuidado dos interesses da Doutrina e a sua propagação; a manutenção de sua utilidade pela conservação da integridade dos princípios reconhecidos; o desenvolvimento de suas consequências;

2ㅇ o estudo dos princípios novos, suscetíveis de entrar no corpo da Doutrina;

3 A concentração de todos os documentos e informações que podem interessar ao Espiritismo;

4ㅇ A correspondência;

50 A manutenção, a consolidação e a extensão dos laços de fraternidade entre os adeptos e as sociedades particulares de diferentes países;

6o A direção da Revista, que será o jornal oficial do Espiritismo, e à qual poderá ser acrescentada uma outra publicação periódica;

700 exame e a apreciação das obras, artigos de jornais, e todos os escritos interessando à Doutrina. A refutação dos ataques, se for o caso;

8 A publicação das obras fundamentais da Doutrina, nas condições mais propícias à sua vulgarização. A confecção e a publicação daquelas das quais daremos o plano, e que não tivermos tempo de fazer em nossa vida. Os encorajamentos dados às publicações que poderão ser úteis à causa;

9 A fundação e a conservação da biblioteca, dos arquivos e do museu;

10 A administração da caixa de assistência, do dispensário e do asilo;

11 ํ A administração dos negócios materiais;

12 - A direção das sessões da sociedade;

13 o O ensino oral; 
140 As visitas e instruções às sociedades particulares que se colocarem sob o seu patrocínio;

15ㅇ A convocação dos congressos e das assembléias gerais. (Kardec, 2007, p. 360)

Essas atribuições seriam repartidas entre os diferentes membros da comissão, segundo a especialidade de cada um, os quais, se for preciso, serão assistidos por um número suficiente de membros auxiliares, ou de simples empregados. A declaração anterior exemplifica a atuação simultânea em atividades típicas de conselho administrativo e do corpo executivo.

\section{e) Separação de funções - Ausente}

O presidente e os membros do CA da SPEE poderiam desenvolver atividades do conselho e do quadro executivo.

\section{f) Regimento interno do CA - Presente}

As atividades do CA da SPEE estavam normatizadas em um regimento interno, que tornavam claras as suas responsabilidades e atribuições, objetivando prevenir situações de conflito com os demais órgãos internos e com as organizações vinculadas externas, mas sempre destacando-se a possibilidade de atuação executiva de seus membros.

\section{g) Presidente do CA - Presente}

A ele cabia a responsabilidade básica de assegurar a eficácia e o bom desempenho do conselho e de cada um de seus membros. Estabelecia objetivos e programas administrativos para que o CA pudesse cumprir sua finalidade de representar todos os membros e de acompanhar e avaliar o movimento espírita em geral. Cabia-Ihe presidir as reuniões, compatibilizar as atividades do Conselho com os interesses da sociedade e de seus sócios, organizar e coordenar a agenda, coordenar e supervisionar as atividades dos demais conselheiros, atribuir responsabilidades e prazos, monitorar o processo de avaliações do CA. Deveria, ainda, assegurar-se de que os conselheiros receberiam informações completas e tempestivas sobre os itens pertinentes às reuniões.

\section{h) Comitês - Presente}

Várias atividades do CA da SPEE, inclusive as atividades executivas, que demandariam muito tempo nem sempre disponível nas reuniões - poderiam ser melhor exercidas por comitês especializados. Conforme as necessidades operacionais da SPEE, grupos específicos poderiam ser formados entre os membros do CA conforme a especialidade e disponibilidade de cada um.

\section{i) Avaliação do CA e do conselheiro - Presente}

O IBGC (2009) recomenda avaliações formais e anuais do desempenho do CA e de cada um dos conselheiros. A proposta do CA da SPEE previa congressos (assembléias) ordinárias e extraordinárias para a discussão das idéias e atividades do próprio CA e de seus integrantes, pois a crença de Kardec (1985a) era de que um indivíduo, ou até mesmo um grupo menor, poderia errar ou agir de má-fé, mas a coletividade teria a autoridade legítima para as possíveis e necessárias correções de rumo. Assim, para Kardec (1985a) a força da Comissão Central baseava-se na concordância coletiva baseada nos princípios e nos conceitos doutrinários racionalmente discutidos, onde a razão sempre prevaleceria.

\section{j) Qualificação do conselheiro - Presente}

Para o IBGC (2009), os conselheiros devem possuir:

- Capacidade de ler e entender relatórios gerenciais e financeiros;

- ausência de conflito de interesses; 
- alinhamento com os valores da sociedade;

- conhecimento das melhores práticas de governança corporativa;

- integridade pessoal;

- disponibilidade de tempo;

- motivação;

- capacidade para trabalho em equipe;

- visão estratégica.

Ainda segundo o IBGC (2009), o conselheiro deve ter um enfoque contínuo em relação à sociedade e entender que seus deveres e responsabilidades são abrangentes e não restritos às reuniões do Conselho.

Para o CA da SPEE, o conselheiro seria escolhido pelos demais membros devido à reconhecida capacidade de compreensão do corpo teórico do Espiritismo, além de comprometimento explícito com os preceitos doutrinários, atitudes que não o desabonassem moral e legalmente e ausência de conflito de interesses.

\section{k) Composição do Conselho - Parcial}

A principal condição para integrar o CA da SPEE era a afinidade conceitual, o caráter illibado e a ausência de conflitos de interesse, mas não há menção explícita sobre a diversidade de aptidões dos conselheiros.

Sob a ótica empresarial, o IBGC (2009) recomenda que haja diversidade de experiências, conhecimentos e perfis dos conselheiros, de maneira a se reunir:

- Experiência de participação em outros CA;

- experiência como executivo principal;

- experiência em administrar crises;

- experiência em identificação e controle de riscos;

- conhecimentos de finanças;

- conhecimentos contábeis;

- conhecimentos dos negócios da sociedade;

- conhecimentos do mercado nacional e internacional; e

- contatos de interesse da sociedade.

Obviamente, algumas recomendações do IBGC (2009) como a presença de membros com experiência anterior em outros conselhos, não poderiam ser aplicadas integralmente à SPEE, considerando-se as singularidades dessa organização. As prioridades da SPEE voltavam-se para os aspectos de divulgação teórica e representatividade doutrinária perante a sociedade da época e, para tanto, a presença de conselheiros experientes poderia ser uma condição desejável, mas certamente não era prioritária.

\section{1) Prazo do mandato - Parcial}

O prazo do mandato do presidente do CA da SPEE era de um ano. Já os conselheiros seriam substituídos por falecimento ou outras causas (não especificadas) voluntárias e involuntárias.

\section{m) Idade - Ausente}

Não havia limites de idade para a atuação como conselheiro da SPEE. O IBGC (2009) sugere que se fixe o número máximo de anos de serviço contínuo no CA para se evitar a vitaliciedade. 
n) Porta-voz da sociedade - Presente

O CA da SPEE deveria designar uma só pessoa com a responsabilidade de ser o porta-voz da organização, eliminando-se o risco de haver contradições entre as declarações de seus próprios membros.

\section{o) Avaliação da Diretoria executiva - Ausente}

Diante da inexistência de segregação de funções do conselho e de execução operacional, não havia uma diretoria executiva distinta, já que essa confundia-se com o próprio conselho.

\section{p) Planejamento da sucessão - Parcial}

O CA da SPEE possuía um planejamento de sucessão do seu presidente e membros, mas não de todos os gestores.

\section{q) Datas e pautas das reuniões - Presente}

Ao presidente do CA da SPEE cabia a proposição de um calendário anual de reuniões ordinárias e a convocação de reuniões extraordinárias. A regularidade de agenda estava presente.

\section{r) Documentação das reuniões - Presente}

Para o IBGC (2009), "a eficácia das reuniões do Conselho de Administração depende muito da qualidade da documentação distribuída antecipadamente [ ...] aos conselheiros". Na SPEE, previa-se que, em todas as reuniões do CA e de assembléias, o material a ser discutido já tivesse sido previamente analisado pelos respectivos membros.

\section{s) Atas das reuniões - Presentes}

Previstas nos trabalhos internos do CA da SPEE, os documentos tratados produzidos seriam arquivados e, de maneira sintética, os assuntos e decisões ocorridas nas reuniões eram divulgadas pela publicação mensal oficial (Revista Espírita, com primeira edição publicada em janeiro de 1858).

\section{t) Auditoria independente - Ausente}

Não se menciona a figura de alguém com funções semelhantes ao do auditor independente na documentação consultada.

\section{u) Auditoria interna - Parcial}

A principal função da auditoria interna, conforme o IBGC (2009) é verificar o funcionamento dos controles internos e se os regulamentos, instruções e políticas estão sendo observados na entidade e recomenda-se participação efetiva dos comitês específicos e do CA no planejamento dos trabalhos de auditoria. Não há menção de um grupo específico para verificar e validar os mecanismos e eventos relacionados ao Caixa Central da SPEE (semelhante a um fundo geral utilizado para suprir as necessidades administrativas e sociais da organização), entretanto, Kardec (1985a) destaca que tal Caixa deveria ser objeto de rigorosa contabilidade, sugerindo que deveria haver uma ou mais pessoas encarregadas da movimentação e controle desse fundo.

\section{v) Conselho Fiscal - Ausente}

Para o IBGC (2009), membros do CA não podem participar do Conselho Fiscal e é considerada boa prática a reunião regular do CA (ou representantes indicados) com o Conselho Fiscal para tratar de assuntos de interesse comum. O CA deve fornecer aos membros do Conselho Fiscal cópia integral das atas 
de todas as suas reuniões. Não existia, no Projeto de 1868, algum órgão semelhante tal como modernamente se verifica.

\section{w) Educação contínua dos conselheiros - Parcial}

Segundo o IBGC (2009), o conselheiro deve aprimorar constantemente o seu desempenho e atuar com um enfoque estratégico de longo prazo, além de ser imprescindível que ele participe de programas de treinamento para atualização e reciclagem de conhecimentos. Essa questão, na SPEE, não pode ser considerada em seu pleno significado, uma vez que os seus conselheiros e membros achavam-se no início de um período de consolidação e aprendizado dos próprios princípios doutrinários, relativizando a questão do treinamento constante, ligado a funções técnicas. Os conselheiros da SPEE, entretanto, deveriam elaborar pareceres e opinar sobre diversos assuntos que poderiam gerar má interpretação ou dubiedade nos conceitos doutrinários, o que faz com que fossem incentivados, naturalmente, ao desenvolvimento das próprias idéias.

\section{x) Código de conduta - Parcial}

Devido ao fato de que existe nos próprios princípios doutrinários espíritas a expectativa de conduta de seus adeptos, não existe um código específico relacionado ao comportamento e à postura dos membros do CA e dos colaboradores da SPEE, além daqueles previstos nos estatutos da instituição, mas há preceitos morais desenvolvidos nas chamadas obras básicas do Espiritismo que podem ser considerados um grande código de conduta. Alguns dos problemas detectados por Kardec que o levou a projetar a Comissão Central (Kardec, 1985a) foram o personalismo e o conflito de interesses que poderiam gerar dissidências e cismas, portanto esses foram tópicos especificamente tratados, mas que se alinham com a conduta ética esperada por conselheiros corporativos do IBGC (2009). Adicionalmente, a previsão de assembléias (congressos) gerais foi considerada, por Kardec, uma oportunidade de análise e validação da conduta de seus membros representativos.

\subsection{Análise sintética}

Os dados observados nesta pesquisa apontam que a SPEE, particularmente com relação à sua Comissão Central (assemelhada a um Conselho de Administração), apresentava 50\% (12/24) de presença, 25\% (6/24) de ausência e 25\% (6/24) de presença parcial dos elementos propostos pelo IBGC (2009) como integrantes das práticas de boa governança.

Dentre os elementos ausentes, destaca-se a característica temporal da inexistência de recomendações para a época de que os membros do CA exercessem atividades de gestão, caracterizando um problema de agência, conforme identificado nos itens"e" (Segregação de funções) e "o" (Avaliação da diretoria). Os demais itens ausentes ("b", "m", " $t$ " e " $v$ ") estão vinculados às práticas de organizações atuais, o que pode ser considerado de menor gravidade para a época (apesar de continuar a ser um problema de governança).

Dentre os itens parcialmente presentes, quase todos não foram explicitados por Kardec em seu projeto (Kardec, 1985a), apesar de haver menções implícitas que poderiam sugerir mecanismos de controle e práticas de auditoria, por exemplo, ao se mencionar a necessidade de "uma contabilidade rigorosa", ou ainda, na menção da conduta esperada dos membros da SPEE sem haver a elaboração formal de um código de condutas.

\section{Considerações finais}

Uma preocupação natural exposta por Kardec em seu Projeto de 1868 foi a superação de prováveis cismas no movimento espírita emergente, formado pelos diversos grupos estabelecidos na França e em outros países (principalmente europeus) que poderiam ser gerados pela má interpretação dos princípios doutrinários. Nesse sentido, Kardec propôs a criação de uma Comissão Central para capitanear informalmente a legitimação do corpo teórico espírita. Para tanto, desenhou-se uma estrutura de governança para a SPEE, a qual abrigaria a Comissão Central. 
Para se verificar o grau de conformidade dos elementos de governança da SPEE, comparou-se as características de funcionamento e organização da Comissão Central com as boas práticas recomendadas pelo Instituto Brasileiro de Governança Corporativa, adaptando-se à realidade de organizações não governamentais sem fins lucrativos.

A pesquisa apontou que $50 \%$ dos elementos de governança estavam integralmente contidos na proposta organizacional da Comissão Central da SPEE, enquanto $25 \%$ desses itens estavam parcialmente presentes e, somente, $25 \%$ encontravam-se ausentes. Esses dados demonstram a preocupação de Kardec em estabelecer mecanismos de controle e operação da SPEE condizentes com o que se poderia classificar, atualmente, como boas práticas de governança.

O Projeto de 1868 foi implantado parcialmente, pois o seu idealizador faleceu em 1869, pouco tempo depois da elaboração de sua proposta. Os continuadores da tarefa de consolidação da Doutrina Espírita, promoveram congressos locais, nacionais e internacionais, para a discussão e alinhamento dos princípios doutrinários de maneira a evitar o aparecimento de cismas ou rupturas significativas. Igualmente, os adeptos espíritas mantiveram as principais características do modelo organizacional projetado para a SPEE, firmando-a como referência para a fundação de inúmeros grupos e sociedades espíritas modernas

Sugere-se, para novos estudos, a investigação dos elementos históricos de governança presentes em outros segmentos do Terceiro Setor, a fim de se verificar e comparar as características das respectivas organizações e de suas possíveis influências nas práticas adotadas ontem e hoje.

\section{Referências}

Aguilera, R. \& Cuervo-Cazurra, A. (2009). Codes of good governance. Corporate governance: an international review, v.17. no.3. pp.376-387.

Bardin, L. (2009). Análise de conteúdo. Lisboa: Edições 70.

Berghe, L., Ridder, L. (1999) International Standardization of Good Corporate Governance. Best Practices for the Board of Directors, Kluwer, Boston.

Brigham, E. F. \& Ehrhardt, M. C. (2006). Administração Financeira Teoria e Prática. São Paulo: Thomson.

Coase, R. (1937). The nature of the firm. Economica. v. IV, no. 16, pp.386-405, nov. doi: 10.1111/j.14680335.1937.tb00002.x

Comissão de Valores Mobiliários (2002) - CVM. Recomendações da CVM sobre governança corporativa. http://www.cvm.gov.br/port/public/publ/cartilha/cartilha.doc.

Fama, E. F. \& Jensen, M. C. (1983). Separation of ownership and control. Journal of Law and Economics, 26, 301-325. doi: 10.1086/467037

Federação Espírita Brasileira(1979). Orientação ao centro espírita. Rio de Janeiro: FEB.

Fernandes, R. C. (1994). Privado porém público: o terceiro setor na América Latina. Rio de Janeiro: RelumeDumará.

Fischer, Rosa M. (2002) O desafio da colaboração: práticas de responsabilidade social entre empresas e terceiro setor. São Paulo: Gente.

Flynn, P. \& Hodgkinson, V. A. (2001). The private nonprofit sector: measuring its impact on society. New York: Kluwer Academic.

Frumkin, P. \& Keating, E. K. (2001). The price of doing good: executive compensation in nonprofit organizations. The Hauser Center for Nonprofit Organizations, Working Paper no 8, pp-1-38.

Futter, V. (2002). Nonprofit resources: a companion to nonprofit governance. New York. American Association.

Garcia, Wilson. (1990). O centro espírita. São Paulo: USE.

Gregory, H. \& Simmelkjaer, R. (2002). Comparative Study of Corporate Governance Codes Relevant to the European Union and its member States, Weil, Gotshal, and Manges LLP, New York. 
Hermes, N., Postma, T. \& Zivkov, O. (2007). Corporate governance codes and their contents: An analysis of Eastern European codes, Journal for East European Management Studies, 12: 53-74.

Instituto Brasileiro de Governança Corporativa - IBGC. (2005). Código brasileiro das melhores práticas de governança corporativa. São Paulo. http://www.ibgc.org.br.

Jensen, M. C. \& Meckling, W. H. (1976). Theory of the Firm: Managerial Behavior, Agency Costs and Ownership Structure. Journal of Financial Economics. (v. 3, no. 4), pp. 305-360, October.

Kardec, A. (2007). Obras póstumas. 25 ed. São Paulo: FEB, . (1985a). Fundação da SPEE. Revista espírita. São Paulo: Edicel, v.1, p.155. . (1985b). Sociedade parisiense de estudos espíritas: regulamento. Revista espírita. São Paulo: Edicel, v.1, p.162. v.2, p. 141 . (1985c). O papel da SPEE no estabelecimento do Espiritismo. Revista espírita. São Paulo: Edicel, Olak, P. A. \& Nascimento, D. T. (2008) Contabilidade para entidades sem fins lucrativos: terceiro setor. 2. ed. São Paulo: Atlas.

Organisation for Economic Co-operation and Development - OECD. (1999). Principles of corporate governance. Paris: OECD.

O'reagan, K. \& Oster, S. (2002). Does government funding alter nonprofit governance? Evidence from New York City nonprofit contractors. Journal of Policy Analysis and Management, 21(3), pp 359-379. doi: 10.1002/pam.10050

O'shea, N. (2005) Governance how we've got where we are and what's next, Accountancy Ireland, $37: 33$

Ostrower, F. (2007) Nonprofit Governance in the United States: Findings on Performance and Accountability from the First National Representative Study. The Urban Institute.

Paes, J. E. (2001) Fundações e entidades de interesse social: aspectos jurídicos, administrativos e tributários. Brasília: Brasília Jurídica.

Pires, J. H. (1990). O centro espírita. São Paulo: Lake.

Ross, S. A. (1974). The economic theory of agency and the principle of similarity. In M. Balch, D. MCFadden and S. Wu (Ed.). Essays on Economic Behaviour under Uncertainty. Holland.

Salamon, L. (1999). Estratégias para o fortalecimento do terceiro setor. In: loschpe, E. B. (Org.). 3o Setor: desenvolvimento social sustentado. Rio de Janeiro: Paz e Terra.

Spence, M. \& Zeckhauser, R. (1971). Insurance, information and individual action. American Economic Review, v.LXI, №. 2, pp.380-387.

Spínola, M. M. Centro espírita: os cinco fatores críticos para uma reforma estrutural. Disponível em < http://www.cpdocespirita.com.br/Trabalhos/Cinco\%20Fatores_Mauro.pdf>. Acessado em 05/07/2010.

Steane, P. \& Christie, M. J. (2001). Non-profit boards in Australia: a distinctive governance approach. Corporate Governance: An International Review, v. 9, no. 1, pp. 48-8. doi: 10.1111/1467-8683.00225 